\title{
E-reading among students of the political studies and international relations faculty of the nicolaus copernicus university in torun (Poland)
}

\author{
Beata Stachowiak \\ The Political Studies and International Relations Faculty, Torun, Poland \\ The Nicolaus Copernicus University, UMK, Torun, Poland
}

Email address:

Beata.Stachowiak@umk.pl (B. Stachowiak)

To cite this article:

Beata Stachowiak. E-Reading Among Students of the Political Studies and in-Ternational Relations Faculty of the Nicolaus Copernicus University in Torun (Poland), Education Journal. Vol. 2, No. 1, 2013, pp. 7-12. doi: 10.11648/j.edu.20130201.12

\begin{abstract}
This paper considers students' attitudes towards e-reading. The author presents the results of a study conducted from 2003 to 2012 among students at Nicolaus Copernicus University that examined students' attitudes towards electronic resources. The study utilized the results of other researchers. The results of the study indicate that despite the increasing availability of electronic publications on the Polish market, they are not becoming more popular among students, at least not among those students that comprised the researched group. This is undoubtedly connected with the respondents' modest reading needs, which are being insufficiently developed at Polish schools. After the reforms of 1999, Polish education has focused solely on test-driven examinations of students' knowledge and abilities. The results of the research presented in this paper unambiguously indicate that interest in online magazines, as well as digital libraries in which the holdings are becoming more and more extensive, is decreasing.
\end{abstract}

Keywords: E-Reading, Students, Poland, Information Society

\section{Introduction}

The First Congress in Polish Computer Science, held in Warsaw in December 1994, was the beginning of the computer science construction in Poland. The Strategy of Information Technology Development in Poland was accepted at the end of the conference. The summary of this document included 10 recommendations that were supposed to be a guideline for Polish authorities and citizens. Poland entered the computer science era with considerable delay compared to Western democratic countries. This was connected, first and foremost, with the fact that until 1989 Poland was one of the countries behind the "Iron Curtain." Access to modern technologies was thus limited to a considerable extent. Since then, 18 years have passed and much has changed during this time, including the field of electronic services. Online newspapers appeared and became available during this time, as well as digital libraries that were still enriching their resources. E-readership grew along with the traditional readership. This issue is particularly important in the context of groups such as students, pupils, etc. The scope of e-services is described in many publications, for example, in reports published by the Main Statistical Office including the cyclic publication, Social Diagnosis. Eurostat also provides statistics concerning e-services. These data are valuable, as readers have access to results of studies conducted according to the same methodology across various countries in the European Union. Information can be reviewed as far as age, sex, education, and employment are concerned, as well as other factors. Besides, entities such as Telecommunication operators and banks carry out own studies to construct offers that increase the scale of services including services provided electronically. The studies mentioned have nationwide scale; the results obtained are very valuable. However, the exploration of local character cannot be forgotten, for example, limited to one university, pupils at secondary schools in a defined region, or seniors from a city. The results of these studies are very valuable because they allow for the preparation of local strategies of operation aimed at, for example, preventing and counteracting adverse phenomena such as digital exclusion, technoholism, etc. However, the results of studies having a local nature are rarely spread among vast circles of recipients in this country, or abroad. 


\section{The Characteristics of Studies}

The author applies the definition e-readership in a broader sense that it is commonly understood. This notion means not only using electronic newspapers, digital libraries, repositories, but also choosing some services provided with electronic systems via libraries and aiming to lend a book in its traditional form. The representative sample that has been the subject matter of the studies conducted since 2003 are the students of the Political Science and International Relations Faculty at Nicolaus Copernicus University. The purpose of the author's exploration was not only to diagnose the scale of the popularity among students of services provided electronically, but also to monitor the availability of new information and communication technologies. The selection of the research group was occasional and connected directly with the author's workplace and conducted classes. The author undertook part of studies to increase the efficiency of classes. The research technique was a diagnostics survey.

\section{Students' Access to a Computer and the Internet}

The results obtained by the author between 2003 and 2012 indicate that access of to a computer significantly improved among students of the Political Science and International Relations Faculty. In 2012, almost all respondents - 99\% - indicated unlimited access to a computer; $91 \%$ of the interviewees declared having a laptop. Interviewees' access to the Internet has also improved considerably: at the beginning of the studies, in 2003, only $34 \%$ of respondents had unlimited access to the network, whereas this index amounts to $89 \%$ in 2012 . Detailed data from 2003-2012 were not presented in Figure 1. Information concerning Internet access indicates that it does not meet needs entirely; according to the author, that status shall be reached due to mobile solutions, which are increasingly popular in Poland. Characteristic features of the subject-matter students sample was the fact that the majority of respondents (99\%) used the Internet in their place of residence; only half respondents indicated the university; only $8 \%$ used hotspots. Detailed data are presented in Table 1. This confirms that the sample tested is supposed to become mobile. Arguably, the results obtained due to testing students from large Polish agglomerations as far as using hotspots is concerned differ from data originating from analysis of students from Torun. It results, first and foremost, from the relatively small number of hotspots in Torun. Data included in Table 1 point in 2012 to one more regularity that is of historical nature. Interest in Internet cafés has been almost completely eliminated, though it was popular in the initial phase of Internet development in Poland.

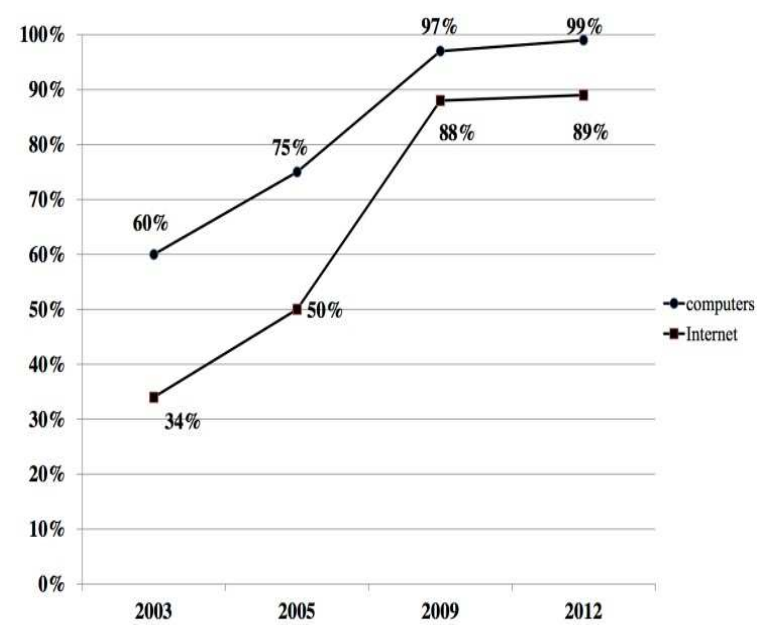

Figure 1. Unlimited access to a computer and the Internet for students at Nicolaus Copernicus University.. References: Own research.

Table 1. Percentage of students stating when the place of using Internet is concerned.

\begin{tabular}{lllll}
\hline Specification & $\mathbf{2 0 0 3}$ & $\mathbf{2 0 0 5}$ & $\mathbf{2 0 0 9}$ & $\mathbf{2 0 1 2}$ \\
\hline Workplace & 2 & 7 & 3 & 3 \\
University & 21 & 25 & 37 & 47 \\
Internet cafe & 38 & 9 & 0 & 1 \\
Place of living & 45 & 60 & 98 & 99 \\
Friends & 15 & 14 & 18 & 41 \\
Other place & 5 & 2 & 2 & 56 \\
Hotspot & 1 & 0 & 3 & 8 \\
No answer & & & 0 & 0 \\
\hline
\end{tabular}

References: Own research.

\section{The Popularity of E-Newspapers among Students}

The author had already started to consider issues connected with e-readership in questionnaires dating from 20031 and 2005.2 At that point in time, there were few resources in Poland related to electronic publications. For example, initial funding for the construction of the Polish Internet Library was transferred to the government only at the end of 2002. The online newspaper market was poor. However, some records for the plans of implementing new services appeared in media. Also, the global scale of the Internet caused Polish users to more and more often utilize publications and online newspapers offered by Internet portals from other countries. Thus, in 2003 the author prepared questions for the survey that focused on expectations related to e-services originating and developed in Poland or

\footnotetext{
1 In 2003 the research consisted of 356 students. The research was mainly related to the respondents' attitudes towards e-learning, but the survey also contained question with regards to e-services.

2 In 2005, the research consisted of 300 people, and the topic of the research concerned the digital divide, but also contained some issues related to priority of services for the information society.
} 
that were supposed to have been developed in the not-too-distant future. This future occurred to be a confusing term, as some of the services mentioned in the questionnaire are still unavailable in Poland. The author has examined the respondents' expectations toward online newspapers. And in $2003,68.5 \%$ of the tested students indicated great expectations for e-newspapers, $15.5 \%$ indicated average interest, and $5.9 \%$ indicated slight interest. A lack of any interest was declared by $5.6 \%$ of the students. Only $4.5 \%$ of the respondents had no opinion on the matter. The data proved to be of great interest and indirectly related to the reading needs of the respondents. The author noted such interest for searching for work online: $69.7 \%$ of the tested respondents declared great interest in such a form. In 2005, the results of interviewee testing were similar: $69.2 \%$ of respondents declared great expectations for e-newspapers, $14.7 \%$ declared average interest, $5 \%$ declared a slight interest, $6.6 \%$ declared a lack of any interest, and $4.5 \%$ of the respondents had no opinion on it.

Table 2. The percentage distribution of students declaration concerning the use of online newspapers in 2009-2012.

\begin{tabular}{lll}
\hline Specification & $\mathbf{2 0 0 9}$ & $\mathbf{2 0 1 2}$ \\
\hline I am not familiar with it & 2 & 3 \\
I am familiar with it, & 15 & 23 \\
but I not use & 44 & 50 \\
Sporadically & 39 & 24 \\
Regularly & \\
\hline
\end{tabular}

References: Own research. The value for the nonparametric test verifying if significant statistical differences between 2009 and 2012 exist in terms of online newspapers use is 25,253 . It points to the fact that statistical differences between the two populations exist.

In 2009 and 2012, the author did not ask about expectations towards online newspapers, but about the frequency of use. The use of online newspapers does not belong to the catalogue of priority services; however, this classification is not going to change over the years, 3 it is the service characteristic of the information technology society. The analysis of data obtained by the author allows for the conclusion to be drawn that since 2009 to 2012 some changes happened, and that it had no significant meaning as far as the statistics are concerned. In 2012, in relation to 2009 the index of regular use of this service decreased. In $2009,39 \%$ stated the regular use of it; however, only $24 \%$ declared using it in 2012. The distribution of respondents who sporadically use e-newspapers also changed: $44 \%$ stated as such in 2009 , compared to $50 \%$ in 2012 . The index of students who do not use this service has also increased at the same time - in 2009 this index had a value of $15 \%$; in 2012, it was $23 \%$. This is a concern, considering the fact that students can use many online newspapers that belong to the Nicolaus Copernicus University network, as well as the fact that some titles can be

3 The list of priority services was prepared in 2003. used at home; however, it requires logging into the university's Internet account. To some degree, data obtained by the author concur with results published by Eurostat as far as online newspaper use is concerned. According to it, only $30 \%$ of students from Poland declared that during last three months they had used online newspapers in 2011. This index is low when we compare the data with results of students from Finland - 94\%, Lithuania - 84\%, Czech Republic - 67\%, Germany - 63\%, and Slovakia - 49\%. The students' low interest for online newspapers, which remained low for several years, is worrying. The low level of online newspaper readership among students is worrying, considering the fact that some decrease in paper circulation has been noted, and it has been regularly published by the portal Wirtualne Media.4 It seems that while Polish students have not entered the era of e-newspapers, the process of the digitization of the newspaper market all over the world has become more and more dynamic. For example, the final edition of US edition of Newsweek magazine shall be published on 31 December 2012. This process also includes scientific journals, which are used by students. Scientific periodicals have also been the subject of digitization all over the world.5 For example, according to the British Library's prognosis for British journals up to the year 2020, the proportion of electronic journals shall increase up to $60 \%, 35 \%$ of which will be hybrid, 6 and $5 \%$ of which will only be in printed form; that is, $95 \%$ of journals shall be in digital format [1].

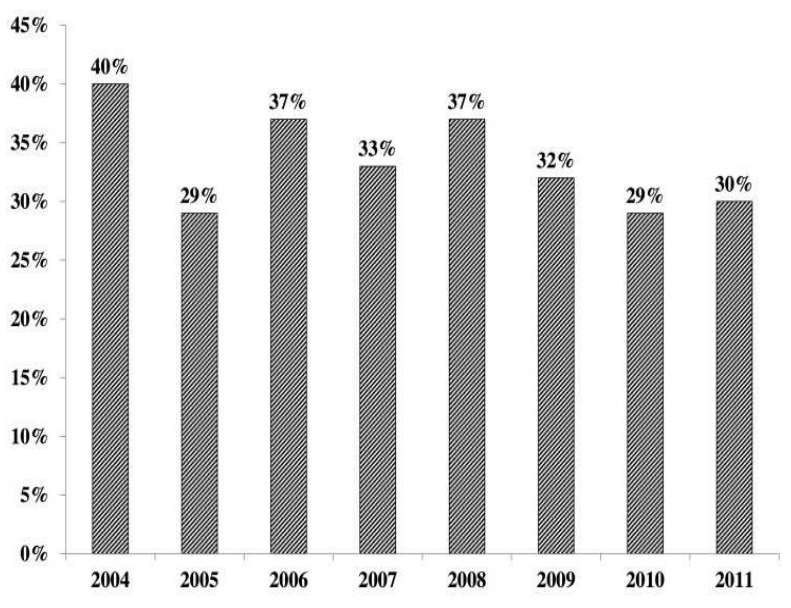

Figure 2. Use of online journals by students in Poland according to Eurostat data. References: http://epp.eurostat.ec.europa.eu accessed on 27 December 2012.

4 The Service Virtual Media is available at the address http:// www. wirtualnemedia .pl.

5 Digitization consists in applying digital technologies for creating electronic documents (for example, electronic journals) as the primary form, contrary to the digitization that consists in converting its traditional form into digital form, for example, scanning [1].

6 The hybrid version is understood as the duality of traditional and electronic editions. 


\section{The Attitude of Students toward E-Libraries}

Addressing the issue of e-readership of digital e-libraries cannot be avoided. By this term, the author understands not only the resources of digital libraries, repositories, bases of articles and scientific publications In the area of the multilingual Internet, but also services provided by the libraries with e-mail, for example, online access to catalogues. This service is a priority service in the information technology society. The changes are noticeable in this field. In 2009 and 2012 the participation of students who didn't have access to online catalogues of libraries remained unchanged: $1 \%$. However, the proportion of students who were familiar with this service, but did not use it, increased. In 2009, such respondents constituted only $3 \%$ of the sample group, but in 2012 it was $11 \%$. Further, the amount of people using the libraries catalogue online increased sporadically - from $21 \%$ up to $35 \%$ in 2012 . This increase occurred at the expense of persons using the services regularly: in 2009 , this figure was $75 \%$, while in 2012 they constituted only $53 \%$ of the tested students. Detailed data are included in Table 3. This fact can be worrying, considering the fact that since November 1995, the catalogues at the university library are only kept electronically. According to the author, this phenomenon requires exploration. Yet there is only one conclusion that can be drawn upon analysis of the data: respondents from 2012 used the libraries more rarely than students tested in 2009. This includes both the traditional, and according to data presented in the next section of this paper, and the digital libraries. The decline of reading among students is confirmed by the following fact: the author included in the survey a question concerning the most popular e-services provided by the university. In $2009,74 \%$ of the students indicated librarian services; in 2012 , this was barely $26 \%$.

Table 3. The percentage distribution of the students' declarations concerning the use of online catalogues of public libraries in 2009-2012.

\begin{tabular}{lll}
\hline Specification & $\mathbf{2 0 0 9}$ & $\mathbf{2 0 1 2}$ \\
\hline I am not familiar with it & 1 & 1 \\
I am familiar with it, & 3 & 11 \\
but I not use & 21 & 35 \\
Sporadically & 75 & 53 \\
Regularly &
\end{tabular}

References: Own research. The value for the nonparametric test verifying if some significant statistical differences between 2009 and 2012 exist in terms of using online newspapers is 54,947. It indicates that statistical differences between the two populations exist.

At present, the resources of Polish Internet libraries are not impressive; limitations are most often connected to issues of copyright. The resources stored in digital libraries usually come from public domain, but some publications belong to the authors who signed author's license that detail the conditions of making the document available online. Digital libraries that operate in Poland are associated with the Federation of Digital Libraries, which on 4 July 2012 attracted 92 members. In writing about digital libraries, some commercial ideas cannot be omitted: for example, the online reading room ibuk.pl.7 It is available for readers interested in books available on the market and payment is required for access. However, for students at Nicolaus Copernicus University, free access is provided to $532 \mathrm{PWN}$ publishing companies concerning matters of social, political, economic, medical, science, and linguistics. Moreover, students can use digital libraries from other countries.

Despite such possibilities, interest in digital libraries, such as in the case of on-line newspapers, is relatively low. The results of the study located in Table 4 indicate that only $20 \%$ of respondents use these resources regularly, approximately $40 \%$ use them sporadically, and over $30 \%$ do not use digital libraries at all. Summing up, fewer students declared that they used digital libraries in 2012 as compared to 2009; however, the differences in this category are not significant as far as the statistics are concerned, but over time this could become significant. The study conducted in 2012 indicated that among students who use them sporadically and regularly, a two percentage point decrease took place, while an increase from $33 \%$ to $37 \%$ of persons who do not use digital libraries was noticed at the same time. The decline of the indexes connected with reading is worrying. This brings sad consternation that students read less. Considering the weight of the problem, reading levels should be monitored over the next years. If this tendency continues, the university and lecturers shall face serious problems.

Table 4. The percentage distribution of students' declarations concerning the use of the online catalogues of public libraries in 2009-2012.

\begin{tabular}{lll}
\hline Specification & $\mathbf{2 0 0 9}$ & $\mathbf{2 0 1 2}$ \\
\hline I am not familiar with it & 5 & 4 \\
I am familiar with it, & 33 & 37 \\
But I not use & 40 & 38 \\
Sporadically & 22 & 20 \\
Regularly &
\end{tabular}

References: Own research. The value for the nonparametric test verifying whether significant statistical differences between 2009 and 2012 exist in terms of using online newspapers is 2,647. It indicates to the fact that statistical differences between two populations exist.

The authoress in this research, the author did not consider the use of tablets, as e-reading was not the main scope of this research. However, the increase in the sales of tablets and e-readers should be observed. One question remains unanswered: whether they remain fashionable toys or if they are going to be used effectively.

\section{Conclusions from the Study and Recommendations}

The conclusions resulting from the author's study can be

\footnotetext{
7 The service ibuk.pl is available at the website http: // www. ibuk.pl /strona_glowna.html.
} 
contained in one statement: students read less and less often, and the level of reading translates directly into the level of e reading. If a person does not read, an e-reader will not change matters. A person could be interested in new gadgets - an e-reader, for example - but this interest could be brief. The results of the author's study are concurrent with a 2010 study conducted by the Workshop of Study on Reading of the National Library, 8 which indicated that $46 \%$ of people from Poland had no contact with a text exceeding three pages of typescript or three pages on a computer's monitor within last month. This group included pupils, students, and persons holding a university diploma [2]. The same study indicated that $56 \%$ of Poles had not read a book, cookbook, or dictionary, whether in hard copy or electronic form. To compare the data, this index in France was $31 \%$, and in Czech Republic barely 17\%. To make matters worse, $33 \%$ of interviewee students and pupils declared that they had no contact with a book last year. Persons who have such a level of reading cannot write a BA dissertation or MA dissertation independently. What is more, the National Library's study indicated that $67 \%$ of respondents had not used the library service, and $72 \%$ had not bought a book. If we take into the consideration the results of Mariusz Jędrzejko's research, who beginning in 2007 carried out tests of 500 students as far as Internet resources for writing assessment tests, BA dissertations, or MA dissertations are concerned, 9 the data has become very disturbing. This brings the consternation that is frequently voiced at conferences, which states that a majority of young people does not approach Internet resources critically. They are also convinced that the Internet contains all data and consider Wikipedia as a scientific resource. This explicitly testifies that levels of education have decreased.

If the worldwide tendency is the digitization of newspapers and libraries, such low indexes among tested students can be explained by low reading needs and financial restrictions connected with the purchase of an e-reader or tablet. However, e-books can be read on laptops. A limitation can also result from the price of a book: in Poland, 23\% VAT is added to electronic books, whereas 5\% VAT is added to traditional books. The other restriction is the improvement of Polish students' attitudes. Many students make copies of books or download them in PDF format from such services as Chomikuj.pl, thus violating copyright laws. Poland is a country where the level of IT piracy is relatively high, 10 though this situation is improving every year. Poland is still

8 Research concerning readership is conducted every two years, at the end of a calendar year. Data originating from 2012 have been not published yet.

9 The research of Mariusz Jedrzejko indicate that 54\% of students from public schools (in $2007-34 \%$ ) and $72 \%$ of students from non-public schools (in 2007 - 57\%) used Wikipedia as a main source for writing in 2009

10 Data on the scale of the information technology hacking In Poland can be found at the address http: // portal. bsa. Org / globalpiracy 2011 / downloads /opinionsurvey /survey_poland. pdf and http: // portal.bsa. org/ globalpiracy2011/downloads/press/pr_poland_pl.pdf. far from UE-15 countries, or countries such as the United States or Canada. Piracy not only concerns computer applications, but films, music, and literature as well.

There are a few reasons for this situation, but the main solution seems to be new and reformed schools. The system of exams that finish every phase of education supports neither self-improvement nor unconventional ways of thinking. Pupils are learning how to solve tests, to think according to a definite key, but not self-reliance and creativity. The next reason for such low indexes is the fact, as the studies are now available for almost everybody, that the index of the schooling rate in academic year 2010/2011 was $53.8 \%$; in $1990 / 91$ it was only $12.9 \%$. The next reason is cultural changes: for the youngest, reading books has been replaced by watching TV and surfing on Internet, often without thinking.

First of all, for the changes to happen, more input should be put on working with texts, creating bibliographical lists by students, and exacting the knowledge of articles by lecturers. The broader use of electronic resources is necessary. However, the change of lecturers' attitudes towards electronic publications should change; it is treated with great care in Poland. Scientists not always consider it as reliable [3].

\section{Summary}

According to the author, from the teacher's point of view, including academics, the e-reader used by students for reading is not necessary. The priority is analyzing texts, drawing conclusions, assessing content in a critical way, and developing thoughts creatively. But Polish school should change; unfortunately, the reforms conducted in 1999 do not support individual thinking, but only prepares students to pass tests. Thus, in the process of education more emphasis should be put on working with source texts, including electronic texts. Also, teachers' approaches towards e-sources should change, as currently many academics are very cautions in this respect. What is more, students should be expected to prepare references that include electronic sources. They should also be aware that popular search engines do not provide full lists of literature. Those changes will have another positive aspect: they will make the works of students more individual.

The presented research results indicate the necessity for continuous monitoring of the use of e-sources. The results of monitoring will allow for undertaking actions that counteract negative tendencies, e.g., the decrease of e-reading described in this article.

\section{References}

[1] M. Nahotko, Polish electronic newspapers: present condition. $\mathrm{W}$ : Electronic publications in the development of Polish science. Edited by Ms. Maria Czyżewska. Białystok: The publishing company of Economic Academy, 2012, pp. 81-92. 
[2] R. Chymkowski, People excluded from the paper culture. The comment to the test of social reach of the book. The fragments are obtained from the resources available in the National Library [access: http://www.bn.org.pl/download/ document/1297852774.pdf].
[3] P. Milewska Paulina, Electronic publications in the work of young scientist. The analysis of the results of survey tests conducted in the Łódź province. W: Electronic publications in the development of Polish science, edited by Ms. Maria Czyżewska. Białystok: The publishing company of Economic Academy, 2012, pp. 33-34. 